\title{
Open Underlay Mesh Reinforced Large Incisional Hernia Repair-Prospective Observational Hospital Based Study
}

\author{
Umer Mushtaq, Ishfaq Ahmad Gilkar, Javid Ahmad Peer, Shaukat Jeelani, Asgar Aziz, \\ Farzanah Nowreen, Yaser Hussain Wani, Yaqoob Hassan, Drjavidahmad Peer*
}

University of Kashmir, Srinagar, India

Email: ${ }^{\text {D }}$ rdoc.javid15@gmail.com

How to cite this paper: Mushtaq, U., Gilkar, I.A., Peer, J.A., Jeelani, S., Aziz, A., Nowreen, F., Wani, Y.H., Hassan, Y. and Peer, D. (2019) Open Underlay Mesh Reinforced Large Incisional Hernia Repair-Prospective Observational Hospital Based Study. Surgical Science, 10, 94-105. https://doi.org/10.4236/ss.2019.103013

Received: March 4, 2019

Accepted: March 16, 2019

Published: March 19, 2019

Copyright $\odot 2019$ by author(s) and Scientific Research Publishing Inc. This work is licensed under the Creative Commons Attribution-NonCommercial International License (CC BY-NC 4.0). http://creativecommons.org/licenses/by-nc/4.0/ cc) (i) (9) Open Access

\begin{abstract}
Introduction: Incisional hernias frequently complicate abdominal surgeries with a varied incidence as reported to be $2 \%-20 \%$. The risk factors of development of incisional hernias include immunocompromised state, diabetes mellitus, smoking, obesity, wound infection at the index surgery, emergency surgery. Materials and Methods: The study design was prospective and included 62 patients with incisional hernias. The patients were evaluated preoperatively on OPD basis with history, clinical examination, baseline investigation, ultrasound abdomen and computed tomogram. Results: The mean age was 48.9 years with male:female ratio of $1: 1.4$. Mean BMI was $30.1 \mathrm{~kg} / \mathrm{m}^{2}$. Out of 62 patients in the study $61.2 \%$ had concomitant hypertension and were on treatment for the same. $30.6 \%$ were clinically hypothyroid, $38.7 \%$ were diabetic and $54.8 \%$ were smokers. There were multiple factors present in patients in the current study which were observed to be possible to have risked the patients to incisional hernias after an abdominal surgery. 21 patients had defect size ranging from 5 to $10 \mathrm{~cm}$ and 41 patients were bearing a hernia of the defect size of $10 \mathrm{~cm}$ or more. The mean operative time was 221.7 minutes. Conclusion: Incisional hernias are a part of surgical practice that would probably glue to it to the end of time. A progression from primitive suture repair with recurrence rates of over $65 \%$ to modern day mesh reinforced repairs with recurrences aimed at $0 \%$ is always welcome. But still then the placement of mesh in different positions or layers of abdominal wall yields different results.
\end{abstract}

\section{Keywords}

Hernia, Mesh, Necrosis 


\section{Introduction}

Incisional hernias frequently complicate abdominal surgeries with a varied incidence as reported to be $2 \%-20 \%$ [1] [2] [3] [4] [5]. The risk factors of development of incisional hernias include immunocompromised state, diabetes mellitus, smoking, obesity, wound infection at the index surgery, emergency surgery [6]. With added morbidity and cost it becomes imperative to salvage the population by having an efficient method to repair such hernias. Repair by primary suturing has recurrences varying from $12 \%$ to $54 \%$. Mesh hernioplasties however have proven to be game changer with a reported recurrence of $2 \%$ to $35 \%$ with variations in the methods the mesh repair is done [7]-[13]. In addition to recurrences, bowel obstruction, enterocutaneous fistulae, pain and disappointing cosmesis seem to be a huge burden.

The largest defect could well be $10 \mathrm{~cm}$ or more [14]. Mesh reinforced techniques have fared well in the management of large incisional hernias. Of all these techniques incorporating mesh into repairs including component separation technique, onlay, sublay with or without peritoneal sandwich technique, it is the sublay technique of mesh reinforcement which displayed best results with recurrence of $3.5 \%$ to $6.3 \%$ [15]. Permanent synthetic meshes have been used in clean wounds with low infectious complications and excellent recurrence rates [16] [17]. These are nonabsorbable meshes made of polypropylene (PP), expanded polytetrafluoroethylene, polyester, lightweight PP, or a combination of these materials used to obtain a "tension-free" closure in incisional hernias [18].

This study was taken up to determine sublay or retromuscular mesh reinforcement as an acceptable technique to repair incisional hernias.

Aims and objectives:

1) To study the Postoperative wound events

2) Recurrence

3) Operative time

4) Hospital stay

5) Mortality

Inclusion criteria:

Large incisional hernias with defect size more than $5 \mathrm{~cm}$

Exclusion criteria:

1) Incisional hernias with defect size less than $5 \mathrm{~cm}$

2) Patient with known collagen diseases

3) $\mathrm{BMI}>40$

4) Patients on lifelong steroids, HIV

5) COPD with extensive uncontrolled disease

6) Hepatic cirrhosis

7) Renal failure on hemodialysis

\section{Materials and Methods}

The study was done in the post graduate department of general surgery and al- 
lied in SMHS hospital, an associated hospital of Government Medical College, Srinagar, J\&K. The study period spanned the time interval between November 2014 to November 2018. The study design was prospective and included $62 \mathrm{pa}-$ tients with incisional hernias. The patients were evaluated preoperatively on OPD basis with history, clinical examination, baseline investigation, Ultrasound abdomen and computed tomogram. History of patients included nature of comorbidity, nature of index surgery, wound events at the index surgery and symptomatology. Clinical examination would determine the site, size of defect, contents. CT scan was indispensable to characterise the defect, classify and determine loss of domain. The patients were evaluated for nutritional embarrassments and attempts were made to rectify the same preoperatively like blood transfusion, serum albumin, BMI. Cessation of smoking for at least 4 weeks before surgery and weight reduction before surgery was ensured. On the day of surgery, preoperatively the patients were prepared with local part preparation, single shot of tetanus toxoid and 3rd generation cephalosporin. Skin incision was made around previous scar with its excision. Abdominal wall layers were dissected with sharp instruments, scalpel and metzenbaum scissors, with limited use of electrcautery. Space was created behind bilateral recti to allow placement of heavy polypropylene mesh with overlap of fascioaponeurotic edges by at least $5 \mathrm{~cm}$ at each place. Retromuscular, sublay preperitoneal mesh hernioplasty without aponeuroplasty with a heavy weight polypropylene mesh was done. The mesh was fixed in place with non-absorbable polypropylene sutures at least 24 in number at places which could possibly avoid wrinkling of mesh and overlap the fascial edges by $5 \mathrm{cms}$ at least in all directions, as shown in Figure 1. A couple of suction drains were kept under skin flaps to counter seroma formation. Age, sex, defect size, defect location, operative time, post-operative wound events like seroma formation, wound infection, abscess formation, early recurrence were noted down. The results were tabulated and subjected to statistical analysis.

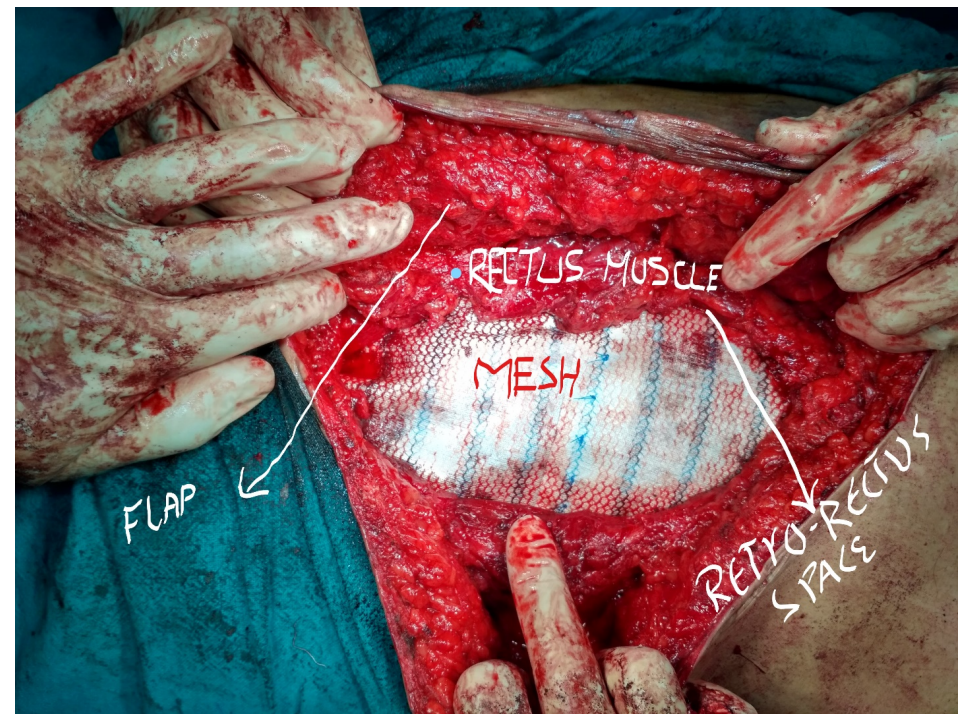

Figure 1. Intra-operative picture of mesh placement. 


\section{Results}

\subsection{Age}

The mean age was 48.9 years, SD 17.52. The patients were grouped on the basis of age into 3 groups. Patients within age 30 - 60 years predominated the study with higher incidence of incision hernias (Table 1, Figure 2).

\subsection{Sex Distribution}

Males patients exceeded in number than female counterparts in presenting incisional hernias with a male female ratio of 1:1.4 (Table 2, Figure 3).

Table 1. Showing age distribution.

\begin{tabular}{cc}
\hline Age Group & Number of patients \\
\hline$<30$ years & 7 \\
$30-60$ years & 39 \\
$>60$ years & 16 \\
\hline
\end{tabular}

Table 2. Showing sex distribution.

\begin{tabular}{cc}
\hline Sex & Number of Patients \\
\hline Male & 36 \\
Female & 26 \\
\hline
\end{tabular}

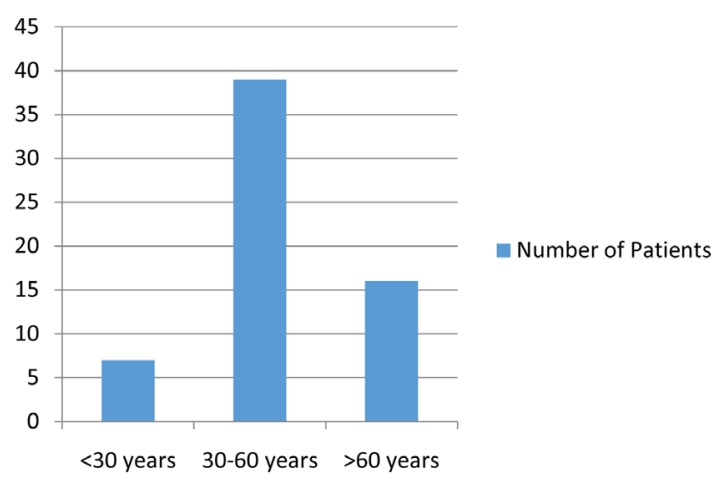

Figure 2. Showing age distribution.

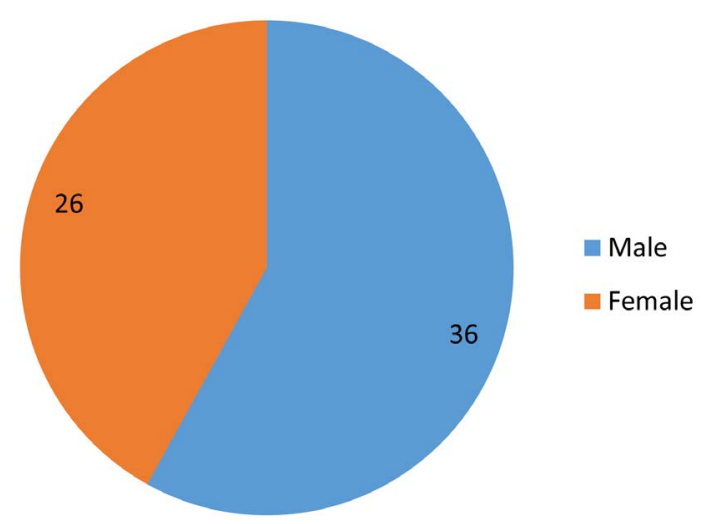

Figure 3. Showing sex distribution. 


\subsection{Body Mass Index}

Body mass index of the patients in our study varied and thus the patients were grouped into mild, moderate and severe obesity depending upon the variable and a group with normal BMI. About $70 \%$ of the patients had obesity of varying grades. Mean BMI was $30.1 \mathrm{~kg} / \mathrm{m}^{2}$. With $\mathrm{P}$ value of 0.27 which is statistically insignificant. As shown in Table 3, Figure 4.

\subsection{Comorbidity}

The patients presenting with incisional hernias were found to have medical comorbidities viz. Diabetes Mellitus, hypothyroidism, hypertension etc. Out of 62 patients in the study $61.2 \%$ had concomitant hypertension and were on treatment for the same. $30.6 \%$ were clinically hypothyroid, $38.7 \%$ were diabetic and $54.8 \%$ were smokers. With $\mathrm{P}$ value of 0.06 which is statistically insignificant. There was an overlap of comorbidities with more than one present in each patient (Table 4, Figure 5).

\subsection{Risk Factors}

Incisional hernia occurs in patients with a previous surgery in abdomen which together with faulty technique is fostered by a considerable risk factor in the individual. There were multiple factors present in patients in the current study which were observed to be possible to have risked the patients to incisional hernias after an abdominal surgery. These are enumerated in Table 4. Obesity (69.3\%), wound dehiscence $(54.3 \%)$ at the index surgery, smoking (54.3\%) were the ones which predominated the list. With a $\mathrm{P}$ value of 0.22 which is statistically insignificant. As shown in Table 5 and Figure 6.

Table 3. Showing body mass index.

\begin{tabular}{ccccc}
\hline BMI & Male & Female & Total & \% age \\
\hline$<25$ & 14 & 5 & 19 & 30.6 \\
$26-30$ & 12 & 5 & 17 & 27.4 \\
$31-40$ & 9 & 14 & 23 & 37.0 \\
$>40$ & 1 & 2 & 3 & 4.8 \\
\hline
\end{tabular}

Table 4. Showing comorbidities.

\begin{tabular}{ccccc}
\hline Comorbidity & $\begin{array}{c}\text { Number of } \\
\text { patients (M) }\end{array}$ & $\begin{array}{c}\text { Number of } \\
\text { Patients (F) }\end{array}$ & Total & \% age \\
\hline Hypertension & 23 & 15 & 38 & 61.2 \\
Hypothyroid & 8 & 11 & 19 & 30.6 \\
Diabetes & 15 & 9 & 24 & 54.7 \\
Smoking & 28 & 6 & 34 & 54.8 \\
\hline
\end{tabular}


Table 5. Showing risk factors.

\begin{tabular}{ccccc}
\hline Risk Factor & Male & Female & Total & $\%$ age \\
\hline Smoking & 28 & 6 & 34 & 54.8 \\
Obesity & 23 & 20 & 43 & 69.3 \\
Wound dehiscence & 16 & 18 & 34 & 54.3 \\
Chronic cough & 9 & 4 & 13 & 20.9 \\
Steroid Intake & 1 & 3 & 4 & 6.4 \\
Collagen Disease & 1 & 0 & 1 & 1.6 \\
Hiv & 0 & 0 & 0 & 0 \\
\hline
\end{tabular}

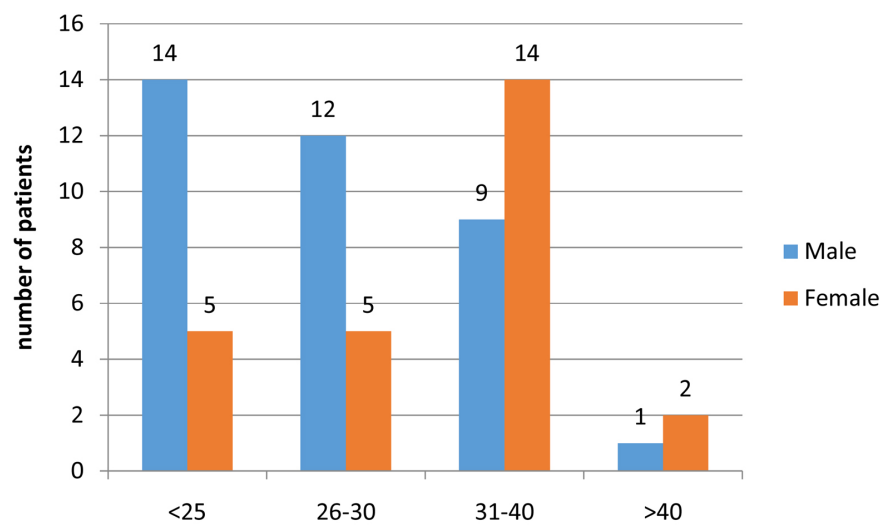

Figure 4. Showing body mass index.

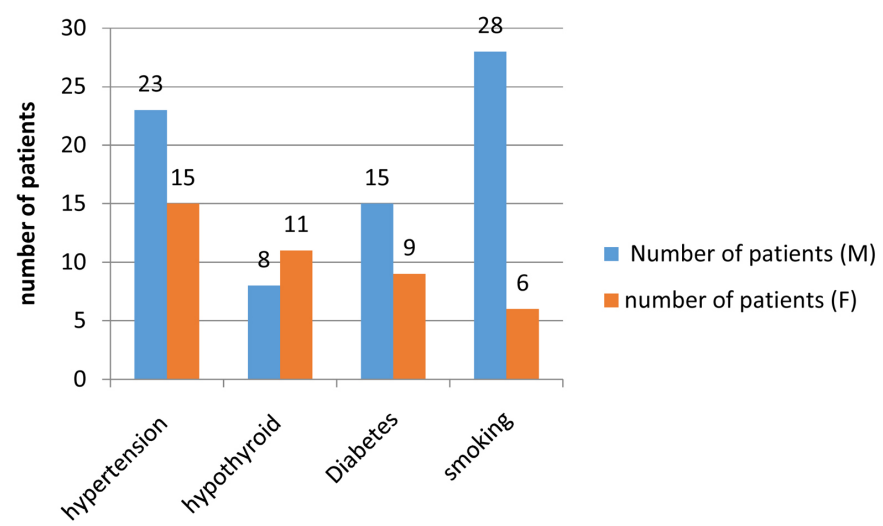

Figure 5. Showing comorbidities.

\subsection{Hernia Defect, Site and Size}

The patients in the study presented with a variety of the symptoms attributed to the varied defect size, site and hernia content. We managed to group the patients into two, one with defect size between 5 to $10 \mathrm{~cm}$ and another with defect size greater than $10 \mathrm{~cm}$ termed large/giant hernias. 21 patients had defect size ranging between 5 to $10 \mathrm{~cm}$ and 41 patients were bearing a hernia of the defect size of $10 \mathrm{~cm}$ or more. The hernia position was described as being upper midline, lower midline or lateral hernias (Table 6). 


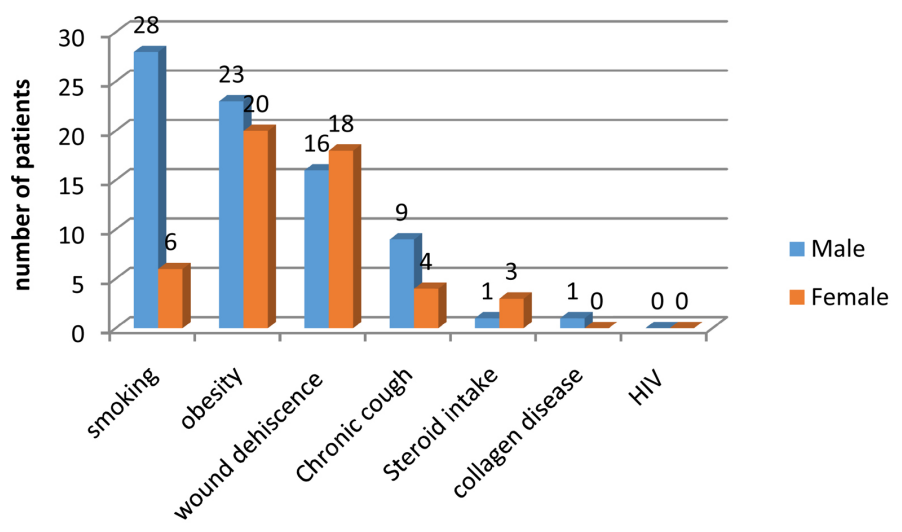

Figure 6. Showing risk factors.

Table 6. Showing hernia characteristics.

\begin{tabular}{cccccc}
\hline Defect & Sex & Upper Midline & Lower Midline & Lateral & Total \\
\hline \multirow{2}{*}{$5-10 \mathrm{~cm}$} & M & 5 & 3 & 1 & 21 \\
& $\mathrm{~F}$ & 2 & 9 & 1 & \\
$>10 \mathrm{~cm}$ & $\mathrm{M}$ & 18 & 8 & 0 & 41 \\
& $\mathrm{~F}$ & 2 & 13 & 0 & \\
\hline
\end{tabular}

\subsection{Post-Operative Wound Events}

Postoperative wound complications in the treatment of incisional hernias are attributed to large fascial dissection and dead space formation. The commonest observed in our study are enlisted in Table 7 and Figure 7. With P value of 0.36 which is statistically insignificant. Post-operative seroma formation is the most predominant wound event/complication, shown as Figure 8.

\subsection{Operative Time}

The mean operative time taken to complete the surgery from incision to skin closure through dissection of layers of abdomen and space behind muscle, placement of mesh, its fixation, placement of a vacuum drain was 221.7 minutes. Operative time tends to be shorter in defects of size $5-10 \mathrm{~cm}$ with operative time of 164.8 minutes.

Duration after drain was removed: mean duration after which the vacuum drains were removed was 10 days.

Hospital stay: mean hospital stay was 8 days.

\subsection{Recurrence}

Incisional hernia recurred in 1 patient within 3 months of postoperative period and 2 patients developed a late recurrence after 1 and half year, a total of $4.8 \%$. All the three patients had wound infection in postoperative period with one of them developing complete dehiscence and early recurrence consequently. 2 patients out of 3 with recurrence were obese with a mean BMI of over 34 . 
Table 7. Showing post. Operative complications.

\begin{tabular}{ccccc}
\hline Wound Event & Male & Female & Total & \% age \\
\hline Seroma & 10 & 17 & 17 & 27.4 \\
Hematoma & 8 & 5 & 13 & 20.9 \\
Wound infection & 5 & 8 & 13 & 20.9 \\
Wound dehiscence & 2 & 3 & 5 & 8.0 \\
Intestinal obstruction & 1 & 0 & 1 & 1.6 \\
Enetrocutaneous fistula & 0 & 1 & 1 & 1.6 \\
Flap Necrosis & 1 & 0 & 1 & 1.6 \\
\hline
\end{tabular}

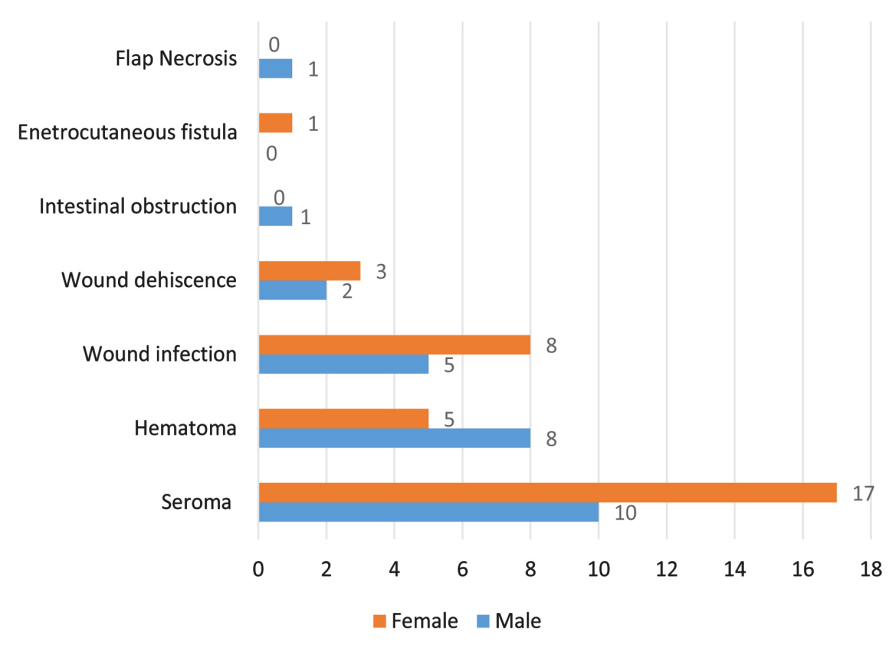

Figure 7. Showing post. Operative complications.

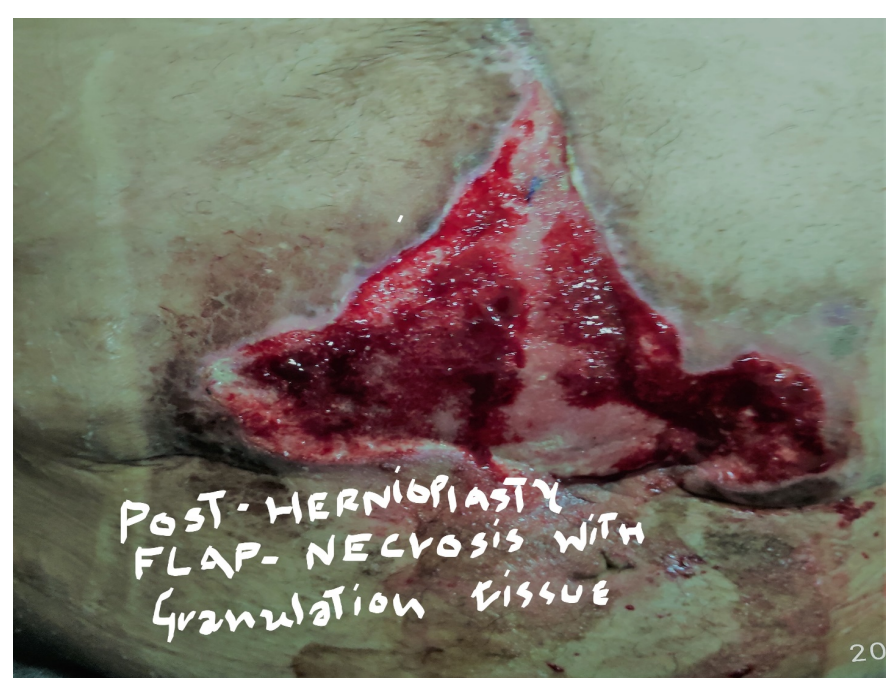

Figure 8. Showing post-operative complication as flap necrosis.

\section{Discussion}

Each incision made on the abdominal wall predisposes the individual to a second operation for repair of incisional hernia. Incisional hernias are caused due to variety of factors including a few from surgical technique adopted and 
pre-existing risk factors or immediate wound events. The risk of development of incisional hernia varies between $2 \%$ to $20 \%$. The repair of incisional hernia repair encompasses a variety of techniques, including primary suture repair through a relaparatomy and closure of fascial edges. Unfortunately, incidence of recurrence in this technique is about $50 \%$, which is too high to make the procedure standard of care in the treatment of incisional hernias. The concept of mesh reinforcement revolutionised the management of hernias [11]. The position in which mesh is placed makes a huge difference in the recurrence of the disease. Overlay, inlay and sublay/underlay placement of mesh in the management of incisional hernias have varied recurrence rates and understandably so in accordance with the Pascals's law, when the intraabdominal pressure rises, equal amount of force is exerted across the mesh. So in Onlay technique, increase in the abdominal pressure exerts lifting force against the mesh, hence more failure rates.

The present study was undertaken in the department of general Surgery of GMC, Srinagar and included 62 patients with incisional hernias with defect size more than $5 \mathrm{~cm}$.

The mean age of presentation was 48.9 years (Table 1 and Figure 2) with male:female ratio of 1:1.4 (Table 2 and Figure 3 ) and mean BMI of the patients was $30.1 \mathrm{~kg} / \mathrm{m}^{2}$ (Table 3 and Figure 4). Similar results were shown in a study published by William S. Cobb et al. [19] and Michael J. Rosen et al. [20]. In our study we found that around $38.7 \%$ of the patients were diabetic, $61 \%$ hypertensive and $30.7 \%$ were hypothyroid (Table 4 and Figure 5), which were relatively similar to findings published by Michael J Rosen [20]. Among the risk factors smoking, obesity and wound dehiscence (Table 5 and Figure 6) at the index surgery were predominantly significant with similar results from the studies by Michael J. Rosen et al. [20] \& R. D. Jaykar [21] et al. Smoking and wound dehiscence render the wound healing, in postoperative phase, poor. According to hernia defect size and site (Table 6), we had two groups to study viz one with maximum defect size greater than $5 \mathrm{~cm}$, less than $10 \mathrm{~cm}$, one third in number $33.8 \%$ and another group with size $>10 \mathrm{~cm}$, two thirds in number $66.12 \%$. Upper midline incisional hernias predominated in males (85\%) and lower midline defects were more in female patients (66\%) of the study group.

Incisional hernia repair warrants exhaustive dissection into the planes of anterior abdominal wall which lead to several wound events and complications uncalled for and unwanted. In this study we had seromas in wounds $27.5 \%$, hematoma formation $21 \%$ and wound infection $21 \%$ commonly encountered. One patient in the study group developed necrosis of skin flaps overlying the mesh in central part. The same patient was managed by debridement and split skin grafting. These were taken care well due in time to halt their progression (Table 7 and Figure 7). The findings were similar to the results of the study by Michael J. Rosen et al. [20] and fared better than those published by Ferdinand Kockerling et al. [22], Nasajpour H. \& Leblanc et al. [23] and William S. Cobb et al. [19] 
who reported an incidence of wound events in postoperative period equal to over $37 \%$ to $64 \%$, seromas which required aspiration or drainage in patients over $33 \%$, wound infections in $39 \%$. Our study recorded a total of $1.6 \%$ enterocutaneous fistula in the study group, $1.6 \%$ bowel obstruction, the results are better than those reported by Leber et al. [24] with enterocutaneous fistulas $3.5 \%$ and mesh to skin fistulas $5.9 \%$, small bowel obstruction $5.4 \%$. Seromas, hematomas and infections in our study were managed conservatively.

The mean operative time recorded from incision to skin closure through dissection of layers of abdomen and space behind muscle, placement of mesh, its fixation and placement of a vacuum drain was 221.7 minutes. Operative time tends to be shorter in defects of size $5-10 \mathrm{~cm}$ with operative time of $164.8 \mathrm{~min}$ utes due to lesser adhesiolysis and dissection. The results almost overlapped with findings from the study done by Michael J. Rosen et al. [20] who reported a mean operating time of 244 minutes in open incisional hernia repair. The mean hospital stay was similar 8 days Vs 7 days, mean time to removal of drain were also alike 10 days vs 12 days. The mean operative time however was less, 164 minutes as reported by Stefano Olmi et al. [25] which could be because less number of anchoring sutures utilised to hold the mesh in position 6 vs 24. Mean hospital stay and mean time to removal of drain were same.

There was no mortality in our study, overlapping the results by Michael J. Rosen et al. [20].

An important aspect of a technique to repair incisional hernias is the recurrence of hernia that follows. We recorded a hernia recurrence of $4.8 \%(n=3)$, in which 1 patient had a very early recurrence within 3 months and 2 patients presented with a recurrence of the hernia after 18 months. The results were independent and overlapped with studies by Ferdinand Kockerling et al. [22] and Stefano Olmi et al. [25] who reported a recurrence $0 \%-13 \%$ in their published data. However our results tend to differ from the ones published by William S. Cobb et al. [19] Michael J. Rosen et al. [20], Jacobas W. A. Burger et al. [26] with reported recurrence of $16.9 \%, 17 \%, 32 \%$ respectively. The only reason which could explain the staggering difference is the follow up which is less in our study i.e. 2 years than theirs, which is not mentioned in one, 2 years and reported as 10 years respectively.

\section{Conclusion}

Incisional hernias are a part of surgical practice that would probably glue to it to the end of time. A progression from primitive suture repair with recurrence rates of over $65 \%$ to modern day mesh reinforced repairs with recurrences aimed at $0 \%$ is always welcome. But still then the placement of mesh in different positions or layers of abdominal wall yields different results. Our study aimed at determining the sublay retromuscular placement of mesh as an acceptable technique with minimal morbidity and maximum benefit in terms of recurrence and post-operative wound complications. The results were favourable with accept- 
able grades of post-operative complications/events and recurrence rates, hence recommended. The future lies in unearthing knowledge of tensile strength and dynamics of distensibility of the abdominal wall which may enable manufacturing prosthesis to be more compatible in hernia repairs than those contemporarily available and of course, evolution of surgical skill is no less important.

\section{Conflicts of Interest}

The authors declare no conflicts of interest regarding the publication of this paper.

\section{References}

[1] Mudge, M. and Hughes, L.E. (1985) Incisional Hernia: A 10-Year Prospective Study of Incidence and Attitudes. British Journal of Surgery, 72, 70-71. https://doi.org/10.1002/bjs.1800720127

[2] Lewis, R.T. and Wiegand, F.M. (1989) Natural History of Vertical Abdominal Parietal Closure: Prolene versus Dexon. Canadian Journal of Surgery, 32, 196-200.

[3] Sugerman, H.J., Kellum Jr., J.M., Reines, H.D., et al. (1996) Greater Risk of Incisional Hernia with Morbidly Obese Than Steroid-Dependent Patients and Low Recurrence with Prefascial Polypropylene Mesh. American Journal of Surgery, 171, 80-84. https://doi.org/10.1016/S0002-9610(99)80078-6

[4] Hodgson, N.C., Malthaner, R.A. and Ostbye, T. (2000) The Search for an Ideal Method of Abdominal Fascial Closure: A Meta-Analysis. Annals of Surgery, 231, 436-442. https://doi.org/10.1097/00000658-200003000-00018

[5] Hoer, J., Lawong, G., Klinge, U., et al. (2002) [Factors Influencing the Development of Incisional Hernia: A Retrospective Study of 2,983 Laparotomy Patients over a Period of 10 Years. Chirurg, 73, 474-480.

[6] van't, R.M., De Vos Van Steenwijk, P.J., Bonjer, H.J., Steyerberg, E.W. and Jeekel, J. (2004) Incisional Hernia after Repair of Wound Dehiscence: Incidence and Risk Factors. American Surgeon, 70, 281-286.

[7] Read, R.C. and Yoder, G. (1989) Recent Trends in the Management of Incisional Herniation. Archives of Surgery, 124, 485-488. https://doi.org/10.1001/archsurg.1989.01410040095022

[8] Manninen, M.J., Lavonius, M. and Perhoniemi, V.J. (1991) Results of Incisional Hernia Repair: A Retrospective Study of 172 Unselected Hernioplasties. European Journal of Surgery, 157, 29-31.

[9] Paul, A., Korenkov, M., Peters, S., et al. (1998) Unacceptable Results of the Mayo Procedure for Repair of Abdominal Incisional Hernias. European Journal of Surgery, 164, 361-367. https://doi.org/10.1080/110241598750004391

[10] Anthony, T., Bergen, P.C., Kim, L.T., et al. (2000) Factors affecting Recurrence Following Incisional Herniorrhaphy. World Journal of Surgery, 24, 95-100. https://doi.org/10.1007/s002689910018

[11] Luijendijk, R.W., Hop, W.C., van den Tol, M.P., et al. (2000) A Comparison of Suture Repair with Mesh Repair for Incisional Hernia. New England Journal of Medicine, 343, 392-398. https://doi.org/10.1056/NEJM200008103430603

[12] Korenkov, M., Sauerland, S., Arndt, M., et al. (2002) Randomized Clinical Trial of Suture Repair, Polypropylene Mesh or Autodermalhernioplasty for Incisional Hernia. British Journal of Surgery, 89, 50-56. 
https://doi.org/10.1046/j.0007-1323.2001.01974.x

[13] Luijendijk, R.W., Lemmen, M.H., Hop, W.C., et al. (1997) Incisional Hernia Recurrence Following "Vest-over-Pants" or Vertical Mayo Repair of Primary Hernias of the Midline. World Journal of Surgery, 21, 62-65.

https://doi.org/10.1007/s002689900194

[14] Ammar, S.A. (2009) Management of Giant Ventral Hernia by Polypropylene Mesh and Host Tissue Barrier: Trial of Simplification. Journal of Clinical Medicine Research, 1, 226-229. https://doi.org/10.4021/jocmr2009.10.1268

[15] Mommers, E.H.H., Leenders, B.J.M., Leclercq, W.K.G., de Vries Reilingh, T.S. and Charbon, J.A. (2017) A Modified Chevrel Technique for Ventral Hernia Repair: Long-Term Results of a Single Centre Cohort. Hernia, 21, 1-10.

https://doi.org/10.1007/s10029-017-1602-2

[16] Fitz Gerald, J.F. and Kumar, A.S. (2014) Biologic versus Synthetic Mesh Reinforcement: What Are the Pros and Cons? Clinics in Colon and Rectal Surgery, 27, 140-148.

[17] van der Linden, F.T. and van Vroonhoven, T.J. (1988) Long-Term Results after Surgical Correction of Incisional Hernia. The Netherlands Journal of Surgery, 40, 127-129.

[18] Muysoms, F.E., Miserez, M., Berrevoet, F., Campanelli, G., Champault, G.G., Chelala, E., Dietz, U.A., Eker, H.H., El Nakadi, I., Hauters, P., Hidalgo Pascual, M., Hoeferlin, A., Klinge, U., Montgomery, A., Simmermacher, R.K., Simons, M.P., Smietański, M., Sommeling, C., Tollens, T., Vierendeels, T. and Kingsnorth, A. (2009) Classification of Primary and Incisional Abdominal Wall Hernias. Hernia, 13, 407-414.

[19] Cobb, W.S., Warren, J.A., Ewing, J.A., Burnikel, A., Merchant, M. and Carbonell, A.M. (2015) Open Retromuscular Mesh Repair of Complex Incisional Hernia: Predictors of Wound Events and Recurrence. Journal of the American College of Surgeons, 220, 606-613.

[20] Rosen, M.J., et al. (2017) Multicenter, Prospective, Longitudinal Study of the Recurrence, Surgical Site Infection, and Quality of Life after Contaminated Ventral Hernia Repair Using Biosynthetic Absorbable Mesh. Annals of Surgery, 205-211.

[21] Jaykar, R.D., et al. (2017) A Clinical Study of Ventral Hernia. International Surgery Journal, 4, 2326-2329.

[22] Kockerling, F., et al. (2018) Treatment of Large Incisional Hernias in Sandwich Technique-A Review of the Literature. Frontiers in Surgery, 5, 37.

[23] Nasajpour, H., Leblanc, K.A. and Steele, M.H. (2011) Complex Hernia Repair Using Component Separation Technique Paired with Intraperitoneal Acellular Porcine Dermis and Synthetic Mesh Overlay. Annals of Plastic Surgery, 66, 280-284. https://doi.org/10.1097/SAP.0b013e3181e9449d

[24] Leber, G.E., Garb, J.L., Alexander, A.I., et al. (1998) Long-Term Complications Associated with Prosthetic Repair of Incisional Hernias. The Archives of Surgery, 133, 378-382. https://doi.org/10.1001/archsurg.133.4.378

[25] Olmi, S., Magnone, S., Erba, L., Bertolini, A. and Croce, E. (2005) Results of Laparoscopic Versus Open Abdominal and Incisional Hernia Repair. Journal of the Society of Laparoendoscopic Surgeons, 9, 189-195.

[26] Jacobus, W.A., Burger, M.D., et al. (2004) Long-Term Follow-Up of a Randomized Controlled Trial of Suture versus Mesh Repair of Incisional Hernia. Annals of Surgery, 240, 578-585. 